\title{
Manajemen User Dan Bandwidth Pada Hotspot Di Kantor BUMD Provinsi Bangka Belitung Menggunakan Router Mikrotik
}

\author{
Reza Oktaviani \\ Program Studi Teknik Informatika \\ STMIK Amikom Purwokerto \\ J1. Let. Jend. Pol. Soemarto, Purwokerto \\ rezaoktaviani991@gmail.com
}

\author{
Dian Novianto \\ Program Studi Teknik Informatika \\ STMIK Amikom Purwokerto \\ J1. Let. Jend. Pol. Soemarto, Purwokerto \\ diannovianto@atmaluhur.ac.id
}

\begin{abstract}
Abstrak - Untuk membangun jaringan pada kantor BUMD, dibutuhkan perangkat- perangkat jaringan seperti Router, Modem, Access Point, kabel UTP agar kebutuhan jaringan terpenuhi. Router digunakan untuk mengatur lalulintas jaringan seperti management bandwidth, pemberian IP (DHCP), authentication user. Modem sebagai koneksi ke ISP, dan Access Point sebagai koneksi wireless ke client. Dalam penyelesaian proyek ini beberapa tahap yang harus diselesaikan yaitu : menentukan area akses jaringan, menentukan topologi jaringan, menentukan alat -alat yang dibutuhkan, menentukan spesifikasi alat-alat yang dibutuhkan, dan menetukan IP yang digunakan sesuai dengan kebutuhan jaringan, dan pengujian terhadap jaringan (implementasi). Hasil yang diharapkan adalah dapat memberi suatu fasilitas yang berfungsi untuk sharing koneksi internet dan dapat menekan biaya agar lebih hemat, dan juga dapat dikembangkan penggunaannya untuk penggunaan atau manfaat lain pada jaringan.
\end{abstract}

Kata Kunci- BUMD, Router, Modem, Access Point, Kabel UTP.

\section{Pendahuluan}

Pesatnya perkembangan teknologi akses informasi jaringan komputer saat ini sangat dibutuhkan untuk menghubungkan berbagai instansi baik di bidang pemerintahan, pendidikan, bahkan di bidang bisnis sekalipun. Dimana banyak perusahaan yang memerlukaninformasi dan data-data dari kantor-kantor lainnya baik dari rekan kerja maupun konsumen. Dalam hal ini sering kali terjadi permasalahan pada jaringan komputer antara lain data yang dikirimkan lambat, rusak, tidak sampai tujuan dan koneksi internet yang masih lambat.Oleh sebab itu jaringan komputer memerlukan sebuah router untuk mempermudah kinerja yang ada di instansi tersebut.

Kebutuhan akan tersedianya media dan fasilitas ini mendorong tumbuhnya fasilitator penyedia akses komunikasi yang cepat dan efisien,yaitu internet.Internet merupakan teknologi yang terus berkembang,internet membuat jarak komunikasi semakin dekat sehingga interaksi manusia dengan informasi dan teknologi semakin mudah,dahulu interaksi antar manusia hanya dilakukan dengan tatap muka,surat menyurat dan telepon,sekarang semua hal tersebut dapat dilakukan dengan internet.Internet memungkinkan kita untuk berinteraksi dengan orang-orang yang berada di belahan dunia lain,kita juga dapat memanfaatkan internet sebagai perpustakaan ilmu pengetahuan.

Meningkatnya kebutuhan manusia dalam hal mengakses informasi secara cepat memicu pengguna jaringan komputer yang lebih banyak. Akan tetapi terkadang jaringan komputer bekerja tidak sesuai dengan keinginan manusia, seperti yang terjadi di Kantor BUMD Provinsi Bangka Belitung seiring terjadi permasalahan pada jaringan komputer antara lain data yang dikirim lambat,rusak,dan bahkan tidak sampai ke tujuan, komunikasi sering mengalami time-out, hingga masalah keamanan.

\section{LANDASAN TEORI}

\section{A. Jaringan Komputer}

Menurut Winarno Sugeng (2010 : 2) Jaringan Komputer adalah mengartikan himpunan interkoneksi sejumlah komputer autonomous. Dalam hal ini penggabungan teknologi komputer dan komunikasi sangat berpengaruh terhadap bentuk organisasi sistem komputer. Model komputer tunggal yang melayani seluruh tugas - tugas komputasi telah diganti dengan sekumpulan komputer berjumlah banyak yang terpisah-pisah tetapi saling berhubungan dalam melaksanakan tugasnya.

\section{B. Manfaat Jaringan Komputer}

Pemanfaatan teknologi jaringan dapat ditinjau dari ketertarikan seseorang dalam menggunakan jaringan dan untuk apa jaringan itu dipakai.

Tujuan dari jaringan diantaranya adalah sebagai berikut :

\section{1) Resource sharing}

Resource sharing bertujuan agar seluruh program, peralatan, khususnya data bisa digunakan oleh setiap orang yang ada pada jaringan tanpa terpengaruh oleh lokasi resource dan pemakainya. Hal ini merupakan usaha menghilangkan kendala jarak. 


\section{2) High Reliablity}

High Reliablity yaitu untuk mendapatkan keandalan tinggi, dengan memilki sumber - sumber alternatif yang tersedia, sehingga jika mesin satu dalam keadaan sibuk maka mesin lain dapat melayani permintaan.

\section{3) Saving Money}

Komputer berukuran kecil memiliki rasio harga/ kinerja yang lebih baik dibanding komputer besar. Sebagai contoh, computer main frame mempunyai kecepatan sepuluh kali lipat komputer pribadi, sehingga harganya lebih mahal. Sehingga perancang sistem memilih mengumpulkan komputer pribadi dalam sistem jaringan, dengan data utama disimpan pada satu atau lebih mesin file server yang dapat dipakai bersama - sama.

\section{4) Scalability}

Scalability bertujuan untuk meningkatkan kemampuan kinerja sistem secara bertahap sesuai beban pekerjaan yang diberkannya, dengan hanya menambahkan sejumlah prosessor, tidak perlu mengganti unit pengelolah utama (server).

\section{Klasifikasi Jaringan Komputer}

Secara umum jaringan komputer di klarisifikasikan menjadi 5 jenis, yaitu:

1) Local Area network (LAN)

Menurut Virgiawan Listanto (2013 : 11) Local Area network (LAN) adalah jaringan milik pribadi dalam sebuah gedung, seperti kantor, sekolah, atau kampus yang berukuran sampai beberapa kilometer. LAN seringkali digunakan untuk menghubungkan komputer - komputer pribadi dan workstation didalam suatu perusahaan untuk memakai bersama sumber daya (misalnya printer) dan saling bertukar informasi.

Jaringan LAN dapat dilihat pada gambar dibawah ini :

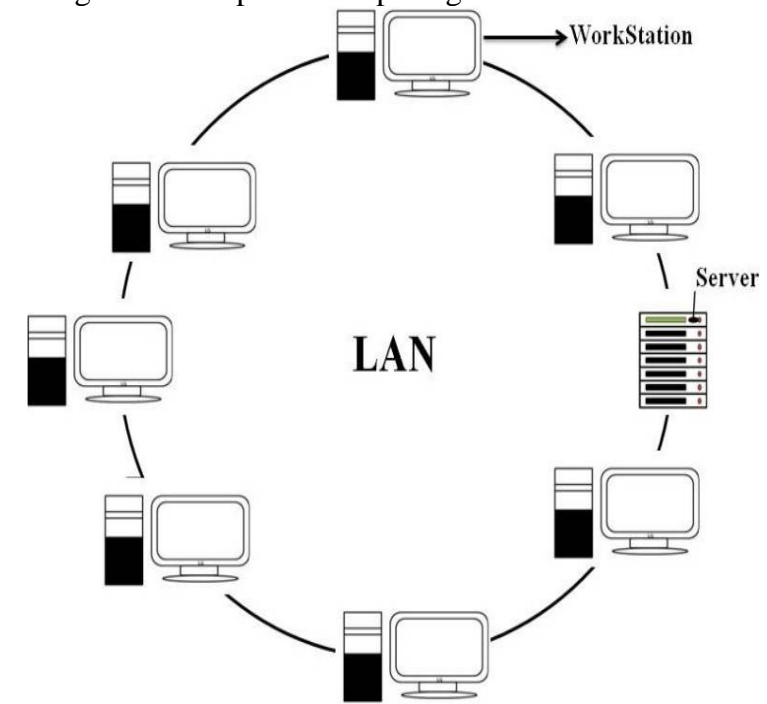

Gambar 1. Jaringan LAN

\section{2) Metropolitan Area Network (MAN)}

Menurut Virgiawan Listanto (2013 : 11) Metropolitan Area Network (MAN) adalah jaringan komputer yang wilayahnya mencakup dalam kota yang dapat dimanfaatkan untuk keperluan pribadi atau umum dengan jangkauan koneksi sampai $50 \mathrm{~km}$. MAN mampu menunjang data dan suara, bahkan dapat berhubungan dengan jaringan televisi kabel. Jaringan MAN dapat dilihat pada gambar :

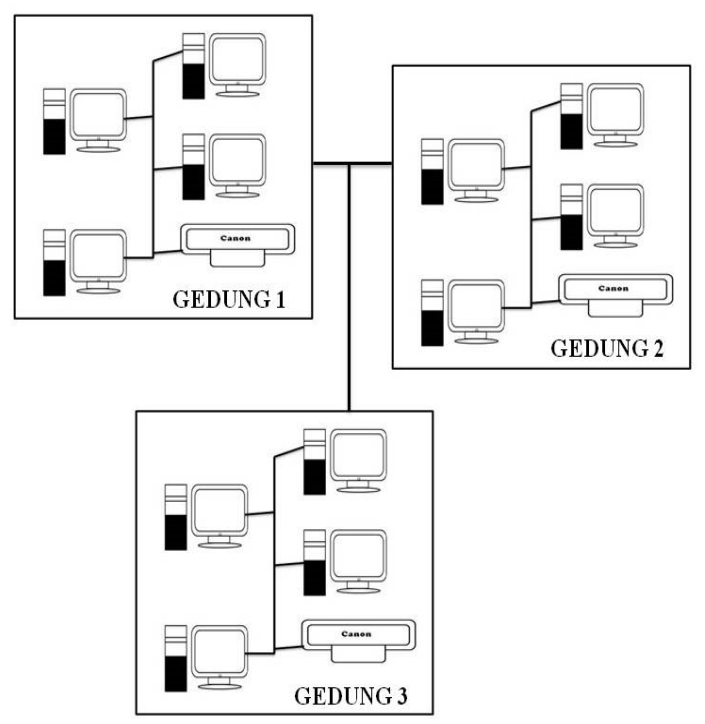

Gambar 2. Jaringan MAN

\section{3) Wide Area Network (WAN)}

Menurut Virgiawan Listanto (2013 : 12) Wide Area Network adalah merupakan jaringan komputer yang mencakup daerah geografis yang luas sebagai contoh yaitu jaringan komputer antar wilayah, kota atau bahkan negara dan benua. WAN terdiri dari kupulan mesin mesin yang bertujuan untuk menjalankan program program (aplikasi) pemakai.

Jaringan WAN dapat dilihat pada gambar 3 :

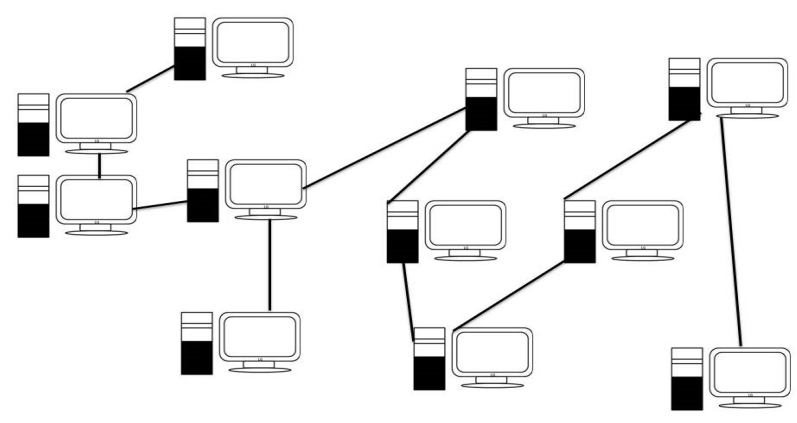

Gambar 3. Jaringan WAN 


\section{4) Internet}

Menurut Virgiawan Listanto (2013 : 13) Internet merupakan kependekan dari Interconected Networking yaitu sistem global dari seluruh jaringan komputer yang saling terhubung menggunakan standart Internet Protocol Suite (TCP/IP) untuk melayani miliaran pengguna diseluruh dunia. Sehingga setiap pemakai yang komputernya terhubung keinternet dapat saling mengakses layanan yang disediakan oleh komputer lain, dalam bentuk pertukaran data, gambar, video, dan suara yang dapat dilakukan secara langsung. Karena komputer yang membentuk jaringan semakin hari semakin banyak, maka dibutuhkan sebuah protokol resmi yang diakui oleh semua jaringan saat ini. Internet juga dapat berfungsi sebagai media informasi dan komunikasi.

\section{5) Jaringan Tanpa Kabel (Nirkabel)}

Jaringan tanpa kabel merupakan suatu solusi komunikasi yang tidak dapat dilakukan dengan jaringan kabel. Jaringan nirkabel biasanya menghubungkan satu sistem komputer dengan sistem lain menggunakan beberapa macam media transmisi jaringan nirkabel, seperti: gelombang radio, gelombang mikro, maupun cahaya infra merah.

\section{Tipe Jaringan}

Dibawah ini merupakan tipe-tipe dari jaringan komputer :

\section{1) Peer to Peer}

Menurut Alan Nur Aditya (2011 : 21) Pada jarngan ini tidak ada komputer client maupun computer server karena semua komputer dapat melakukan pengiriman maupun penerimaan informasi sehingga semua komputer berfungsi sebagai client sekaligus sebagai server. Sistem operasi jaringan model peer to peer memungkinkan seorang user membagi sumber daya yang ada dikomputernya, baik itu file data, printer, dan peripheral lain. Namun, model ini tidak mempunyai sebuah file server atau sumber daya yang terpusat.

a) Kelebihan jaringan peer to peer

- Tidak terlalu mahal, karena tidak membutuhkan satu PC yang sepenuhnya berfungsi sebagai server dan tidak digunakan sebagai media kerja atau sering disebut dengan dedicated server.

- Mudah dalam instalasi programnya, hanya tinggal mengatur untuk operasi model peer to peer.

b) Kelemahan jaringan peer to peer

- Tidak terpusat, terutama untuk penyimpanan data dan aplikasi.

- Tidak aman, karena tidak menyediakan fasilitas pengamanan server yang mencukupi.

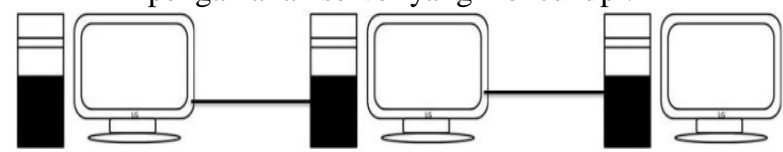

Gambar 4. Jaringan Peer To Peer

\section{2) Client Server}

Menurut Alan Nur Aditya (2011 : 21) Pada Jaringan Client Server terdapat satu atau beberapa komputer server dan komputer client. Computer yang akan menjadi komputer client dan diubah - ubah melalui software jaringan pada protokolnya. Komputer client merupakan perantara untuk untuk dapat mengakses data pada komputer server, sedangkan komputer server merupakan penyedia informasi yang diperlukan oleh komputer client. Arsitektur client-server memiliki kelebihan sebagai berikut:

a) Kelebihan jaringan client server

- Terpusat, sumber daya dan keamanan data dikontrol melalui server..

- Keseluruhan komponen (client / network / server) dapat bekerja bersama.

\section{b) Kelemahan Jaringan client server}

- Biaya pengadaan dan operasionalnya mahal.

- Ketika server drop, keseluruhan operasi pada jaringan akan terganggu.

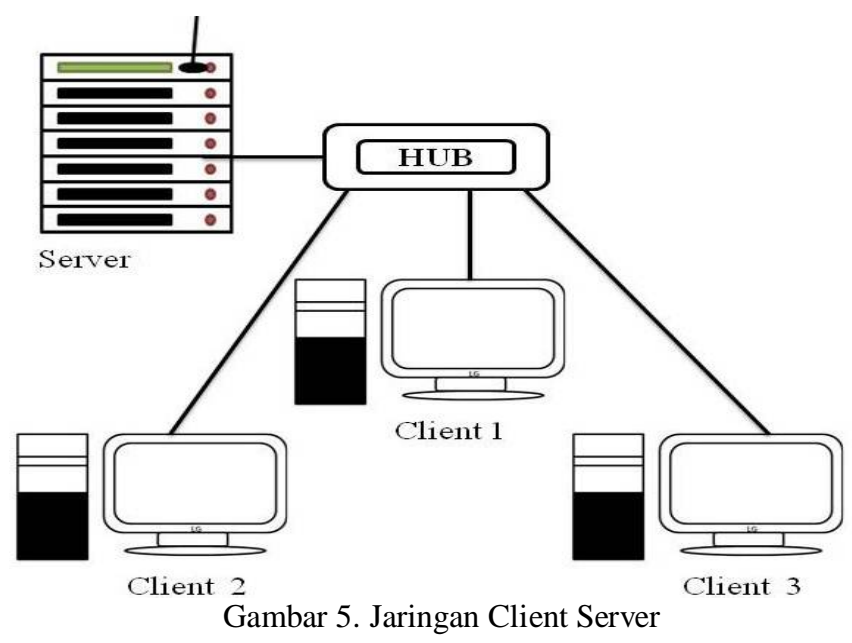

\section{Metode Penelitian}

\section{A. Metode Pengumpulan Data}

\section{1) Obeservasi}

Kegiatan yang dilakukan untuk lebih mengenal objek penelitian yaitu meliputi lingkungan kerja, aktifitas bekerja dan bahan kajian.

\section{2) Wawancara}

Dilakukan dengan orang yang memiliki wewenang dan tanggung jawab di bidang yang diperlukan sehingga informasi tentang penggunaan/pemanfaatan akses internet di Kantor BUMD Provinsi Bangka Belitung bisa mendapatkan data yang tepat dan akurat.

\section{3) Studi Literatur}

Di lakukan untuk mendasari pemikiran dari bahan yang diperoleh dengan cara membaca atau mempelajari literatur 
yang berhubungan dengan pengembangan jaringan berbasis mikrotik.

\section{B. Metode Analisa}

\section{1) Analisa Sistem Berjalan}

Analisa jaringan ini memberikan gambaran tentang system jaringan yang saat ini sedang berjalan di Kantor BUMD Provinsi Bangka Belitung dengan tujuan untuk mengetahui lebih jelas bagaimana cara kerja system tersebut. Kelebihan dan kekuaranga system tersebut diketahui dan dimodifikasi dalam membangun system jaringan yang handal dari system jaringan yang lama, dari hasil analisa yang dilakukan ditemukan beberapa fakta untuk menjadikan bahan menuju pengembangan dan penerapan sebuah system jaringan yang diusulkan sebelumnya. Fakta yang ditemukan dari analisa adalah sudah terkoneksi internet, namun dalam penggunaan bandwidth pada speedy pada Kantor BUMD Provinsi Bangka Belitung tidak teratur dikarenakan akses point speedy berada di ruangan tertentu jauh jangkauannya pada computer user di ruangan lainnya.

\section{2) Analisis Perangkat Keras}

Analisa perangkat keras ini memberikan gambaran tentang perangkat keras yang saat ini digunakan pada Kantor BUMD Provinsi Bangka Belitung. Analisa yang sedang berjalan saat ini menggambarkan bahwa perangkat apa saja yang digunakan oleh setiap user dalam mengakses internet pada Kantor BUMD Provinsi Bangka Belitung tersebut, adapun perangkat keras yang sedang digunakan adalah perangkat computer ( PC) dan laptop, printer serta speedy.

\section{3) Analisis Perangkat Lunak}

Analisa perangkat lunak ini memberikan gambaran tentang perangkat lunak yang digunakan saat ini di Kantor BUMD Provinsi Bangka Belitung dengan tujuan mengetahui jenis - jenis perangkat lunak yang digunakan pada computer user, misalnya system operasi yang digunakan dan aplikasi yang dipakai untuk mengakses internet tersebut baik itu browser atau aplikasi pendukung dalam mengakses internet tersebut. Serta aplikasi pendukung kerja pada pegawai di instansi tersebut.

\section{Metode Perancangan}

Di dalam perancangan ada beberapa tahapan yang dilakukan antara lain perancangan perangkat keras yang dibutuhkan, perangkat lunak atau software baik sistem operasional dan aplikasi serta topologi jaringan yang akan digunakan, serta jaringan yang telah tersedia pada instansi tersebut sebagai berikut :

\section{1) Rancangan Sistem Jaringan Usulan}

Analisa jaringan yang memberikan gambaran tentang system jaringan usulan untuk menggantikan dari system sebelumnya. System yang diusulkan adalah suatu system jaringa yang memiliki topologi star yang berjenis server client, dimana jaringan terpusat pada suatu router yang menjadi control dalam pembagian IP Addres dan bandwidth setiap user yang terhubung langsung ke dalam LAN. Sedangkan untuk router yang akan digunakan adalah satu unit Mikrotik RB951.

\section{2) Perangkat Keras Usulan}

Dari hasil analisa perangkat keras berjalan maka untuk melakukan pengembangan system jaringan di Kantor BUMD Provinsi Bangka Belitung diusulkan beberapa perangkat keras pendukung untuk menutupi kekurangan dalam pembangunan system jaringan di instansi tersebut baik itu perangkat keras untuk akses internetnya maupun peangkat keras pendukung lainnya.

\section{3) Perangkat Lunak Usulan}

Dari hasil analisa perangkat lunak berjalan maka untuk melakukan pengembangan system jaringan di Kantor BUMD Provinsi Bangka Belitung diusulkan berberapa perangkat lunak yang dibutuhkan untuk sarana penunjang pengembangan system jaringan tersebut.

\section{4) Manajemen Jaringan Usulan}

Dari hasil analisa yang dilakukan maka untuk melakukan pengembangan manajemen jaringan di Kantor BUMD Provinsi Bangka Belitung dapat diusulkan jaringan berbasis mikrotik diantaranya adalah pembagian bandwidth internet menggunakan kabel LAN sehingga setiap bidang pada instansi tersebut mendapatkan akses internet secara merata.

\section{Implementasi}

1) Konfigurasi

Konfigurasi merupakan proses pembagian bandwidth IP beserta konfigurasi yang diperlukan untuk membangun jaringan computer yang sudah dirancang.

\section{2) Uji Coba Sistem}

Uji coba merupakan proses evaluasi atau pengujian terhadapa system jaringan sehingga dapat diketahui hasil dari jaringan computer yang telah dibangun.

\section{Pembahasan}

\section{A. Analisa Sistem Jaringan Berjalan}

Kelemahan sistem jaringan adalah kelemahan yang sedang terjadi yang berlangsung di tempat itu. Berdasarkan hasil survey yang telah di lakukan di Kantor BUMD Provinsi Bangka Belitung terdapat kelemahan yang dihadapi mereka yaitu jangkauan akses internet yang tidak terjangkau pada setiap bidang dikantor tersebut, serta belum adanya pembagian bandwidth internet pada kantor tersebut.

1) Analisa Kelemahan Perangkat Lunak 
Analisa kelemahan perangkat lunak yang terdapat pada kantor tersebut adalah sebagai berikut :

Tabel 1. Analisa Perangkat Lunak

\begin{tabular}{|c|c|c|}
\hline No & Nama Software & Keterangan \\
\hline 1 & $\begin{array}{c}\text { Sistem Operasi } \\
\text { Windows 7 }\end{array}$ & $\begin{array}{c}\text { Digunakan pada setiap } \\
\text { klien tersebut }\end{array}$ \\
\hline 2 & $\begin{array}{c}\text { Microsoft Office } \\
2010\end{array}$ & Client \\
\hline 3 & $\begin{array}{c}\text { Antivirus Smadav } \\
\text { Free }\end{array}$ & Client \\
\hline 4 & Browser & $\begin{array}{c}\text { Mozilla Firefox, Internet } \\
\text { Explorer }\end{array}$ \\
\hline 5 & GOM Media Player & Client \\
\hline
\end{tabular}

\section{B. Analisa Kebuhan Jaringan}

Dalam pembangunan jaringan di Kantor BUMD Provinsi Bangka Belitung dibutuhkan perangkat keras dan perangkat lunak tambahan mengingat belum adanya perangkat tersebut untuk pembangunan manajemen jaringan agar dapat berjalan dengan baik.

\section{1) Analisa kebutuhan Perangkat Keras}

Beberapa perangkat keras yang dibutuhkan dalam membangun jaringan tersebut adalah sebagai berikut :

Tabel 2. Analisa Perangkat Keras

\begin{tabular}{|c|c|c|c|}
\hline No & Nama Hardware & Jumlah & Keterangan \\
\hline 1 & $\begin{array}{l}\text { Router Mikrotik } \\
\text { RB 951Ui 2HnD }\end{array}$ & 1 Unit & $\begin{array}{ll}\text { - } & \text { Wireless Standart } \\
& 802.11 \mathrm{~b} / \mathrm{g} / \mathrm{n} \\
- & \text { Wireless Tx } \\
& \text { power 30dbm } \\
- & \text { Antenna Gain } 2 \mathrm{x} \\
& 2,5 \mathrm{dBi} \\
- & \text { POE Input } \\
- & \text { POE Output Port } \\
& 5 \\
- & \text { Dimentions } \\
& 113 \times 138 \times 29 \mathrm{~mm}\end{array}$ \\
\hline 2 & $\begin{array}{l}\text { SWITCH } \\
\text { TL-SF10116D }\end{array}$ & 1 Unit & $\begin{array}{l}\text { Port } 16 \text { to } 28 \text { ports } \\
\text { Media Interface } \\
-\quad \text { RJ } 45100 \text { Ohm } \\
-\quad \text { UTP Cable } \\
-\quad 10 / 100 \text { base } \\
\quad \text { Swicthing } \\
\text { features } \\
\text { - Number of ports } \\
10\end{array}$ \\
\hline
\end{tabular}

C. Denah Jaringan Yang Sedang Berjalan

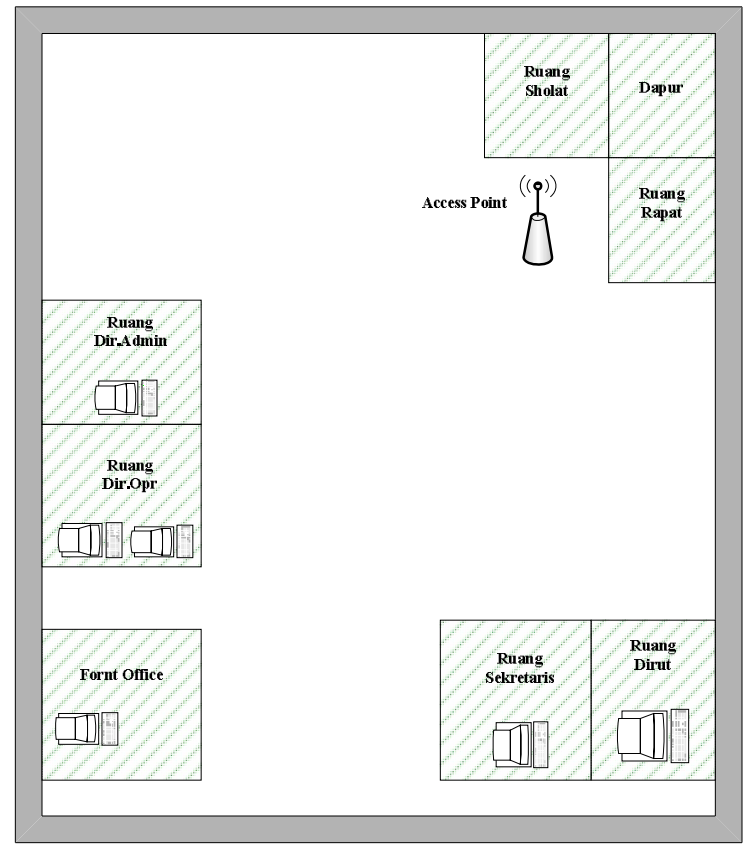

Gambar 6. Topologi Jaringan Yang Sedang Berjalan

D. Denah Jaringan Usulan

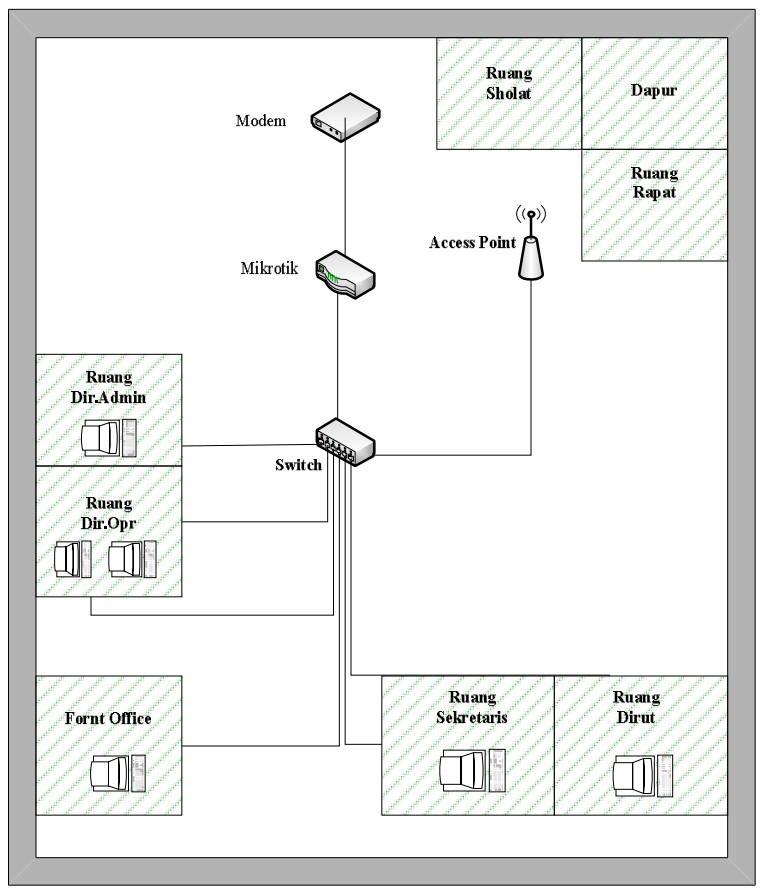

Gambar 7. Topologi Jaringan Usulan 


\section{E. Rancangan Flowchart}

Flowchart mikrotik adalah rancangan yang digunakan untuk cara yang digunakan untuk menginstallasi mikrotik. Adapun rancangan sebagai berikut :

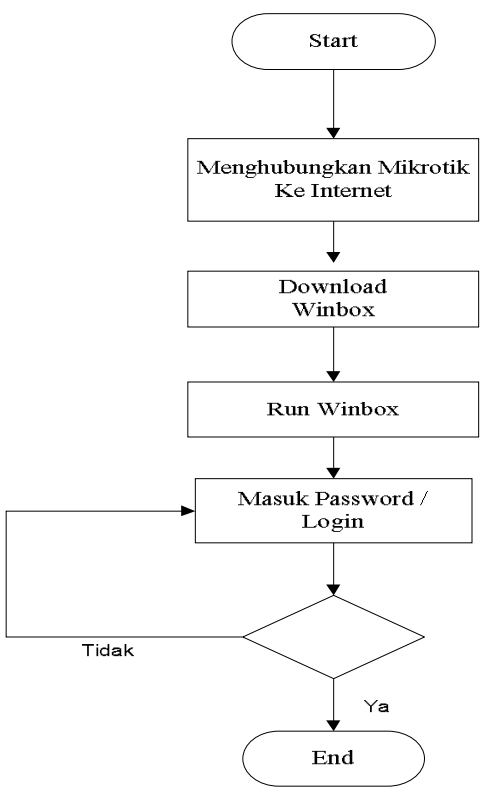

Gambar 8. Flowchart Mikrotik

\section{1) Flowchart Konfigurasi}

Dalam proses pembangunan jaringan, dalam hal ini perlu adanya sketsa rancangan flowchat yang digunakan untuk menggambarkan pembangunan jaringan. Sketsa tersebut dibentuk dalam sebuah flowchart. Flowchart adalah rancangan yang mendeskripsikan fungsi-fungsi yang digunakan, flowchart pengembangan ini dapat dilihat sabagai berikut :

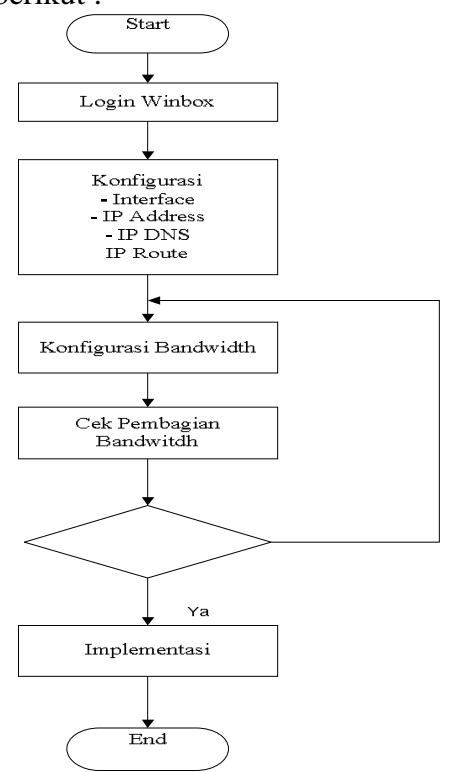

Gambar 9. Flowchart Konfigurasi

\section{2) Flowchart Konfigurasi Access Point}

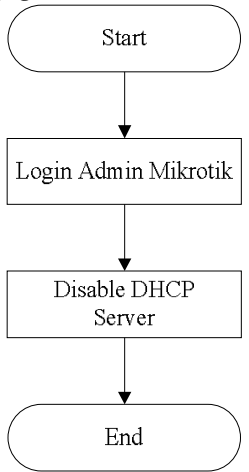

Gambar 10. Flowchart Konfigurasi Access Point

\section{F. Implementasi}

Implementasi merupakan tahap pengembangan rancangan menjadi jaringan hotspot server.Pada awal bagian ini akan dijabarkan spesifikasi perangkat keras dan perangkat lunak pada jaringan yang akan diimplementasikan.Disamping itu juga akan disajikan konfigurasi mikrotik dengan wireless access point dan pengecekan server mikrotik laptop dengan kabel.

Implementasi Konfigurasi Mikrotik Routerboard $951 \mathrm{Ui}$ -

a. Pertama buka winbox,lalu untuk connect,klik kolom connect seperti pada gambar berikut:

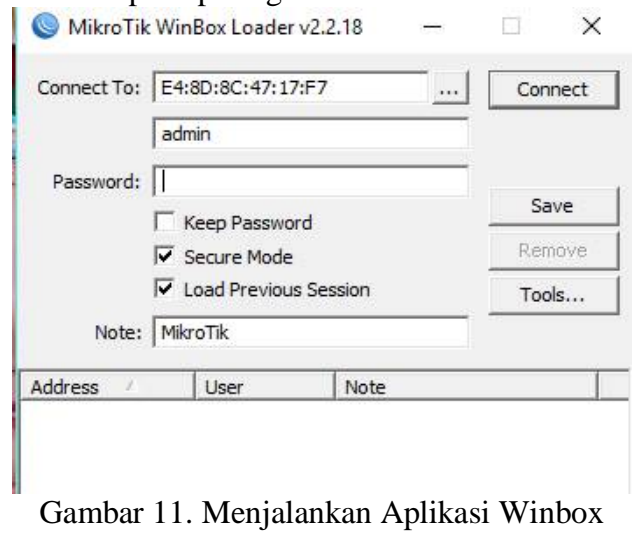

b. Selanjutnya buka Interface, untuk merubah nama ruang,di file name ether2 diganti menjadi ruang 1,lalu klik ok,seperti gambar berikut:

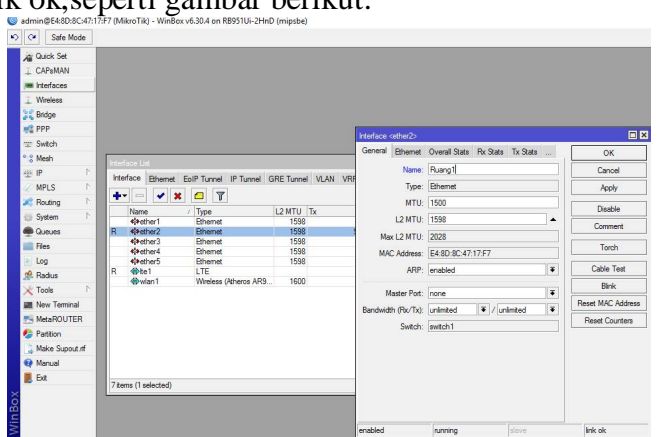

Gambar 12. Menggantikan Nama Ether 
c. Selanjutnya pilih menu IP, kemudian klik DHCP Client.

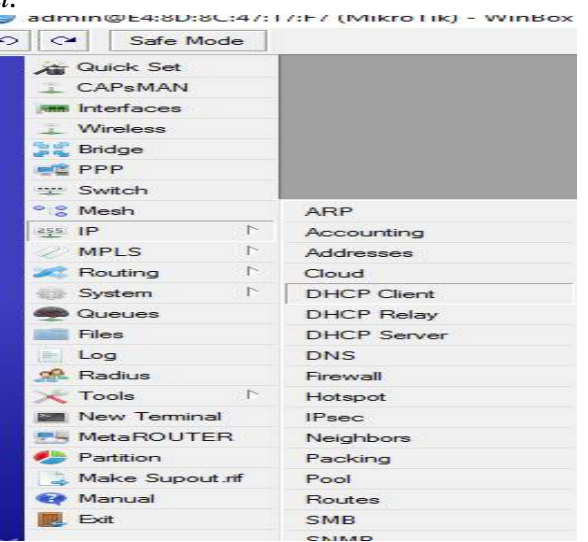

Gambar 13. Tampilan Konfigurasi IP DHCP Client

d. Pada DHCP Client klik tanda (+), lalu muncul new DHCP Client,pada kolom interface etherldiganti dengan internet,lalu klik ok seperti gambar berikut.

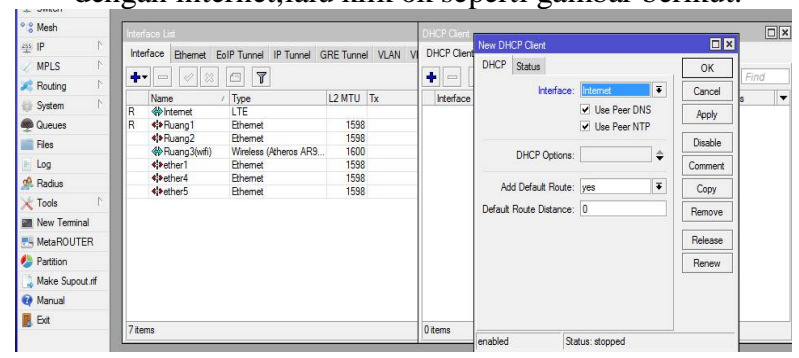

Gambar 14. Mengubah Nama Interface

e. Selanjutnya untuk koneksi,klik New Terminal,lalu ketik ping google.com

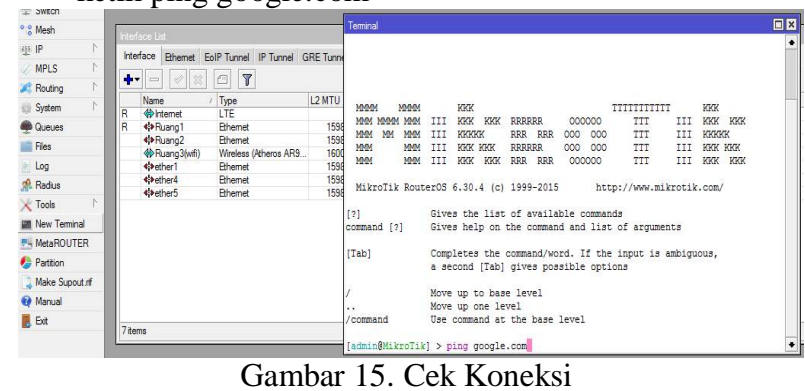

f. Selanjutnya kalau sudah connect, maka tampilan akan seperti ini

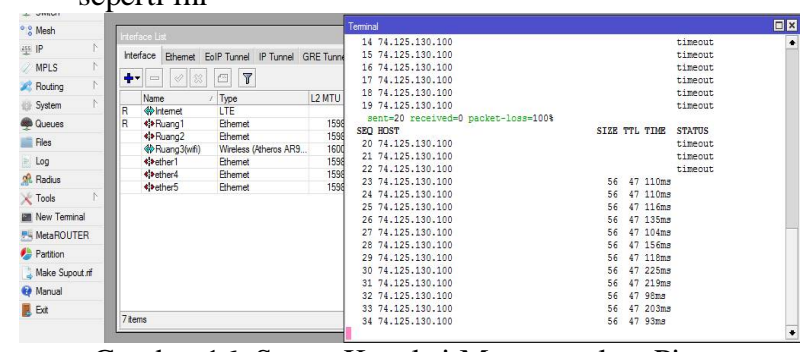

Gambar 16. Status Koneksi Menggunakan Ping. g. Selanjutnya pilih menu IP kemudian klik menu Address

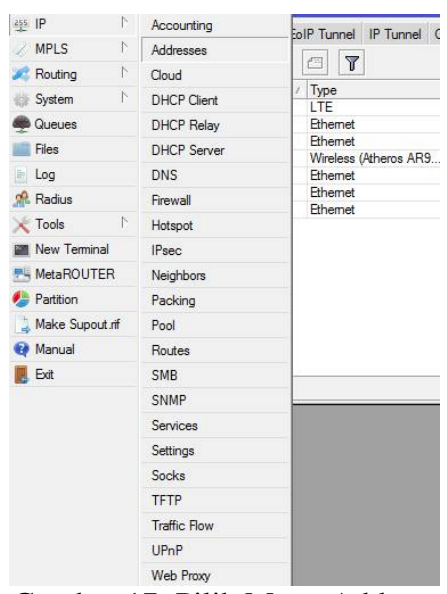

Gambar 17. Pilih Menu Address

h. Setelah mengklik menu address,klik tanda (+), maka akan muncul New Address.Di kolom address, aturlah IP sesuai keinginan.Kemudian Interfacenya diganti dengan ruang1,lalu di apply,terus klik ok.

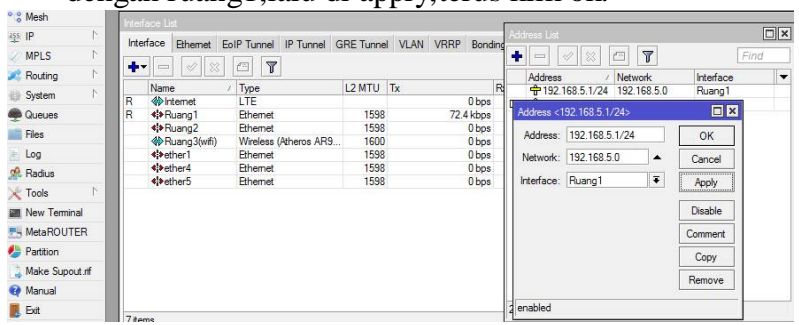

Gambar 18. Mengatur IP di Setiap Ruang

i. Setelah di apply dan di ok,maka tampilan nya akan seperti ini

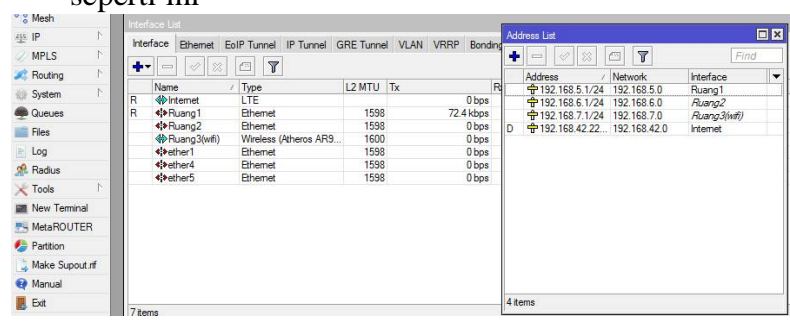

Gambar 19. Tampilan Pengaturan IP di Setiap Ruang

j. Selanjutnya pilih menu IP lalu klik menu DHCP Server,lalu di kolom DHCP server interface name ether1 di ganti dengan ruang1

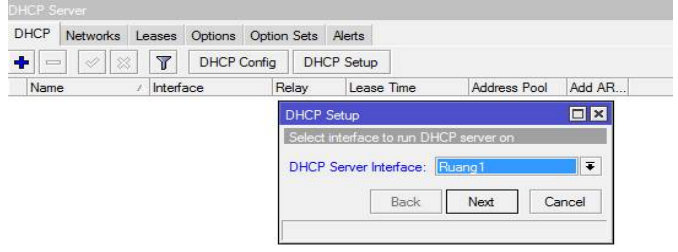

Gambar 20. Menentukan DHCP Server 
k. Setelah nama DHCP server interface selesai di ganti,lalu di next terus sampai finish,maka tampilan nya seperti gambar berikut.

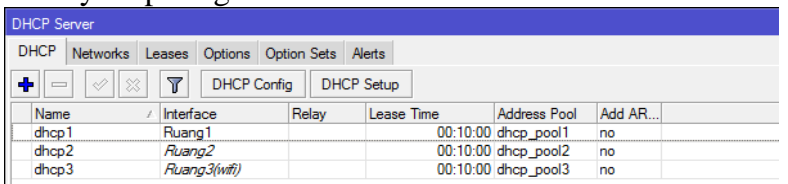

Gambar 21. Hasil Penentuan DHCP

1. Langkah selanjutnya pilih menu IP lalu klik menu Firewall dan pilih menu NAT,kemudian klik tanda (+),setelah itu akan muncul New NAT Rule.Lalu pada kolom Out Interface name etherl diganti dengan internet.

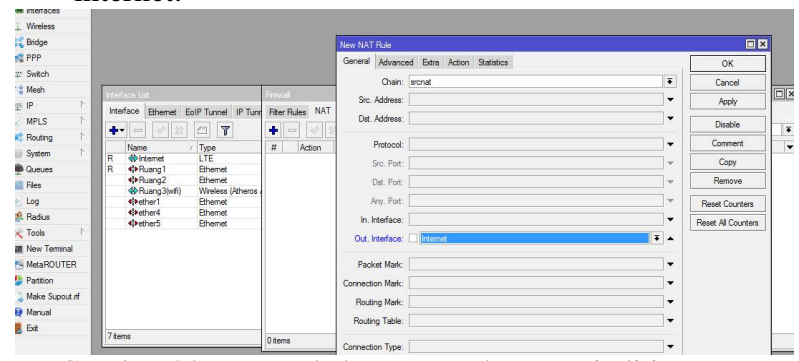

Gambar 22. Mengubah Nama Ether Menjadi internet

m. Selanjutnya klik kolom action, pada kolom action,pilih Masquerade, lalu di apply dan di ok.

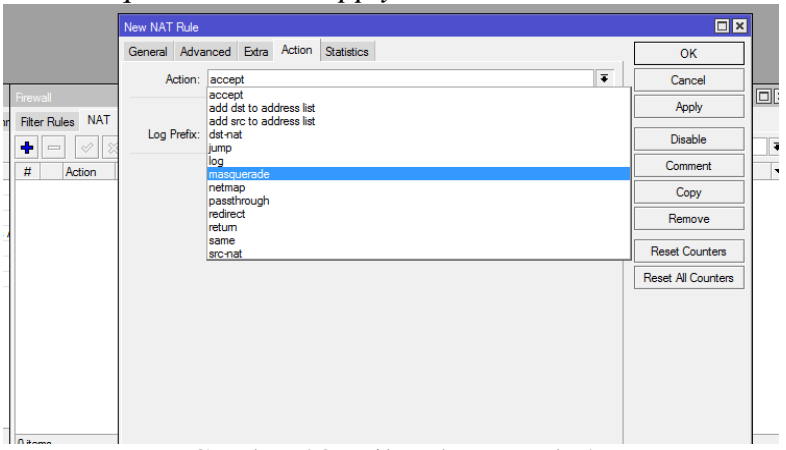

Gambar 23. Hilangkan Tanda !

b. Kemudian pilih menu wireless, klik 2 kali pada kolom ruang3(wifi),pilih kolom wireless, lalu pada :

- Kolom Mode Station pilih ap bridge

- Kolom Band pilih 2GHz-B/G/N

- Kolom Channel Width pilih 20/40 MHz Ce

- Kolom SSID diganti dengan nama (sesuai keinginan) Lalu di apply dan di ok,seperti gambar berikut.

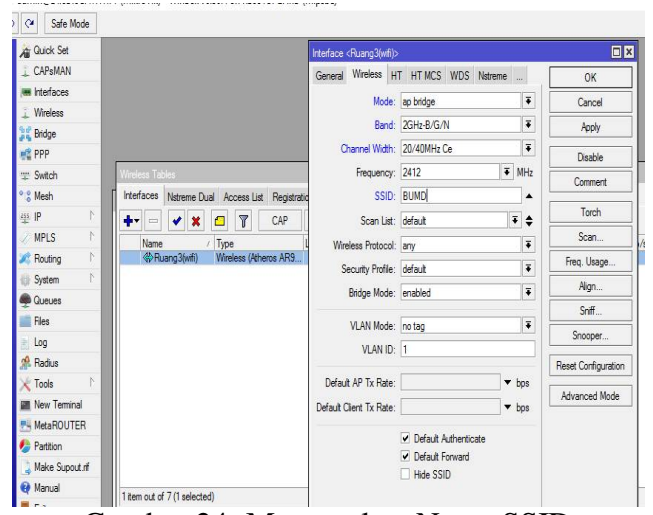

Gambar 24. Menentukan Nama SSID

n. Selanjutnya buka security profiles, klik 2 kali pada kolom bawah WPA Pre Shared lalu pada :

- $\quad$ Kolom Mode pilih dymanic key

- Pada Authetication type,kolom WPA PSK dan WPA 2 PSK di centang.

- Masuki n password sesuai yang diinginkan,lalu di apply dan ok

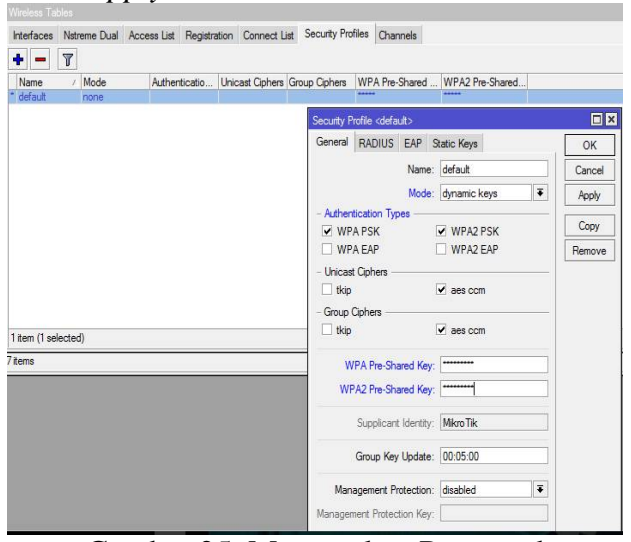

Gambar 25. Menentukan Password

o. Selanjutnya,pilih menu Queue,pilih Simple Queue,klik tanda (+) pada kolom name ether1 pilih ruang 1 . Pada kolom target diganti dengan internet (sumbernya),dikolom Dst pilih ruang1 (harus sesuai dengan kolom name).Kemudian tentukan target upload dan target download.

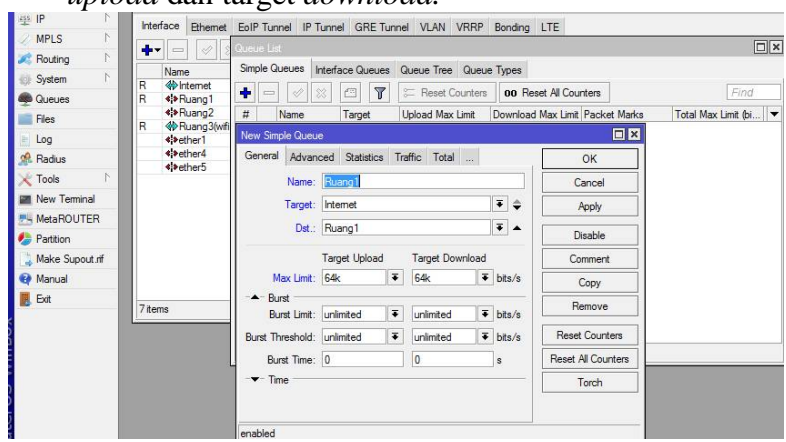

Gambar 26. Penentuan Target Upload dan Download 
p. Setelah semua nya sudah di atur,lalu klik menu apply dan ok,maka hasil nya akan muncul seperti gambar di bawah ini

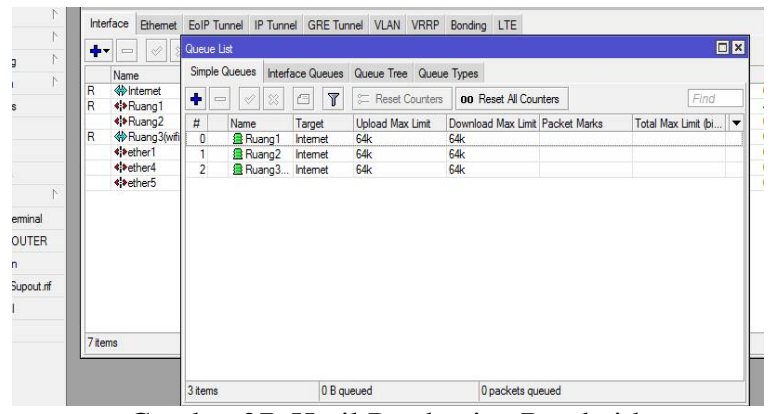

Gambar 27. Hasil Pembagian Bandwith

\section{Penutup}

\section{A. Kesimpulan}

Berdasarkan hasil dari laporan penelitian dan perancangan jaringan "Manajemen User dan Bandwidth Pada Hotspot di Kantor BUMD Provinsi Bangka Belitung" dapat diambil kesimpulan bahwa :

- Dengan DHCP Server masalah pengaturan IP address bisa dipermudah karena kita tidak perlu melakukan setting IP secara manual, karena secara otomatis setiap client akan mendapat IP address dari DHCP server.
- Membatasi jumlah pengguna khususnya yang hanya memiliki username dan password saja yang dapat menggunakan fasilitas internet. Sehingga masalah keamanan khususnya dari pihak luar dapat diminimalisir.

B. Saran

Untuk Memaksimalkan koneksi internet yang terhubung dengan Kantor BUMD Provinsi Bangka Belitung, sebaiknya dibuat satu lagi untuk server proxy.

\section{DAFTAR PUSTAKA}

[1] Candra, Robin. 2008. Perancangan dan Pembuatan Jaringan Server Berbasis Mikrotik, Universitas Kristen Petra : Skripsi. Surabaya

[2] Cartealy, Imam. 2013. Tips \& Trik Mikrotik RouterOS untuk SOHO ANDI. Publisher : Yogyakarta

[3] Herlambang, Moch. Linto, Catur L, Azis. 2008. Panduan Lengkap Menguasai Router Masa Depan Menggunakan Mikrotik RouterOS ANDI. Publisher : Yogyakarta

[4] Mulyadi. 2012. Sistem Perancangan Hotspot Server Berbasis Mikrotik pada SMU 3 Kediri : Skripsi, Kediri

[5] Tarigan, Adrian. 2009. Bikin Gateway Murah Pakai Mikrotik, Gramedia : Jakarta

[6] Yuhefizar, 1969. 10 Jam Menguasai Internet : Seminar, Jakarta 